Document downloaded from:

http://hdl.handle.net/10251/105556

This paper must be cited as:

Puga, AV.; Corma Canós, A. (2017). Direct Conversion of Cellulose into Alkyl Glycoside Surfactants. ChemistrySelect. 2(8):2495-2498. doi:10.1002/slct.201700389

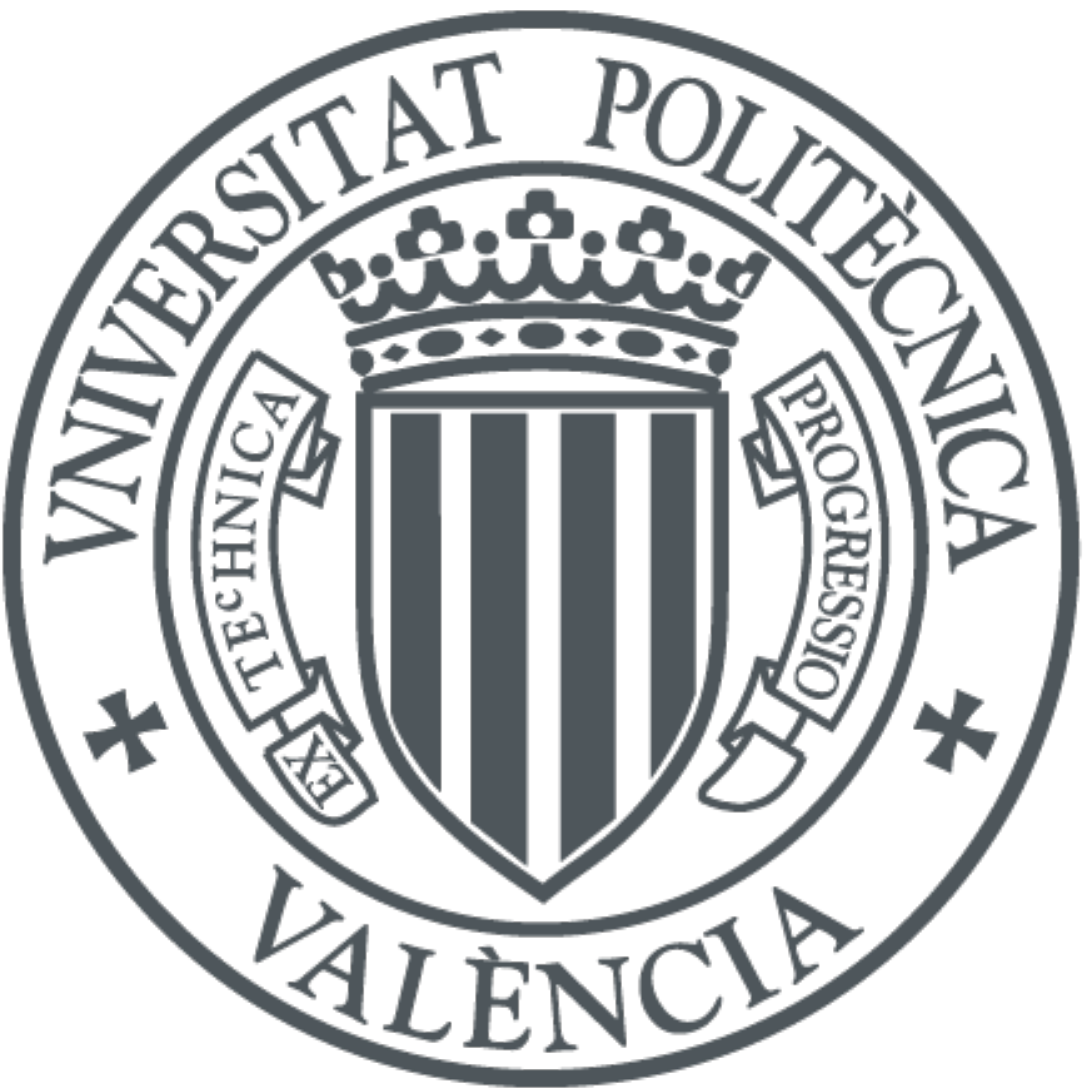

The final publication is available at

https://doi.org/10.1002/slct.201700389

Copyright John Wiley \& Sons

Additional Information 


\title{
Direct Conversion of Cellulose into Alkyl Glycoside Surfactants
}

\author{
Alberto V. Puga, ${ }^{[a]}$ and Avelino Corma ${ }^{*[a]}$
}

\begin{abstract}
The one-step production of biodegradable alkyl glycoside (1-dodecyl mono- and oligoglucosides) surfactants from cellulose has been achieved by direct alcoholysis in fatty alcohol media under Brønsted acid catalysis at near-ambient pressure. The fatty alcohol serves as both solvent and reagent. Addition of small amounts of water prevents dehydration events and thus minimises product and solvent degradation. Furthermore, high initial cellulose loadings and short thermal cycles enable moderate-to-high conversions and selectivities (up to $\approx 70 \%$ ), and low solvent-to-product ratios.
\end{abstract}

In order to establish a sustainable chemical industry, development of efficient routes for the transformation of renewable (non-fossil) feedstocks into commodity or speciality substances is crucial, given their high production volumes and relevance for human welfare. In this context, rational use and exploitation of biomass for the production of chemicals is of paramount importance. ${ }^{[1]}$ Catalysis is a key technology to achieve advances in efficiency and selectivity for these challenging biomass-to-chemicals transformations. ${ }^{[1 a}$, 2] Lignocellulosic materials are promising sources of carbon-based chemicals; amongst them, cellulose holds a prevalent position as the most abundant biomass component. ${ }^{[1 a, 3]}$ Most catalytic cellulose valorisation processes occur along several steps, more specifically via the production of intermediate platform molecules which then serve as starting materials for the generation of the desired end-product. ${ }^{[1 a, 1 c, 1 d]}$ In general, these are hydrolytic pathways, meaning that the first step usually involves saccharification of the polymeric backbone into monomeric glucose, which can be then converted by a variety of transformations to platform chemicals. In best case scenarios, the multi-step processes may take place in one-pot cascade fashion, as is the case for the production of sorbitol, ${ }^{[4]}$ lactic acid, ${ }^{[5]}$ or 5-hydroxymethylfurfural. ${ }^{[6]}$

An archetypal class of speciality chemicals which can be obtained from biomass is that of biodegradable alkyl glycoside surfactants. ${ }^{[7]}$ These are substances of highly specialised performance which can be directly formulated in detergents, personal care products, cosmetics or pharmaceuticals. ${ }^{[7 a]}$ The one-pot, acid-catalysed, transformation of cellulose into alkyl glycosides in ionic liquid media, via mild hydrolysis followed by transacetalisation, was recently reported by us. ${ }^{[8]}$ Medium chain alkyl glycosides have also been produced by similar procedures. ${ }^{[9]}$ An alternative to this method consists in a twostep process based on (i) alcoholysis of cellulose using a short

[a] Dr. A. V. Puga, Prof. A. Corma Instituto de Tecnología Química

Universitat Politècnica de València-Consejo Superior de Investigaciones Científicas

Avenida de los Naranjos, s/n

46022 Valencia (Spain)

E-mail: acorma@itq.upv.es

Supporting information for this article is given via a link at the end of the document.((Please delete this text if not appropriate)) chain alcohol (e.g. methanol) to generate alkyl (e.g. methyl) glycosides, and then (ii) transacetalisation of the isolated intermediate using a long chain alcohol. ${ }^{[8 a]}$ All these procedures involve use of high pressure equipment for step $i$, accurate control of both reaction conditions and appropriate posttreatments after the different steps. In the present work, direct, one-step production of alkyl glycoside surfactants from cellulose in fatty alcohols under homogeneous Brønsted acidic catalysis at near-ambient pressure is demonstrated (Scheme 1). It will be also shown how rational adjustments of experimental conditions are of vital importance for achieving good efficiencies, selectivities and for minimising solvent use and waste generation. In particular, controlled addition of water has proven beneficial since it favours depolymerisation and inhibits product degradation, as noted in our former report on the topic. ${ }^{[8 b]}$

Under the motivation of simplifying the production of biodegradable alkyl glycoside surfactants from cellulose, we explored direct alcoholysis processes using long chain fatty alcohols. In a series of experiments, cellulose was reacted in 1dodecanol media in the presence of small amounts of sulfuric acid $(10.8 \mathrm{mN}, 1.7 \% \mathrm{~mol}$ vs. cellulose) as homogeneous catalyst at different temperatures for short times. These conditions have been previously reported for the production of short chain (e.g. methyl or ethyl) glucosides, ${ }^{[8 a, 10]}$ yet this would not a priori grant efficient formation of longer chain surfactants directly, given the lower reactivity of the fatty alcohols. However, cellulose was readily converted under the reaction conditions studied, and dodecyl glycosides were detected in the final reaction mixtures (see Table 1), thus confirming that the direct one-step formation of surfactants is feasible. Cellulose conversion was quantitative at higher temperatures $\left(\geq 210^{\circ} \mathrm{C}\right)$, yet $\mathrm{C}_{12} \mathrm{G}$ yields and molar balances were low. Presumably, major degradation takes place at temperatures above $200^{\circ} \mathrm{C}$, most likely via further transformation of glucosides into 5-(dodecyloxymethyl)furfural, and subsequently, to dodecyl levulinate and formate (see Scheme 1 and Supporting Information). ${ }^{[8 c]}$ The reaction was performed at lower temperatures, aiming at higher $\mathrm{C}_{12} \mathrm{G}$ selectivities. Indeed, the formation of $\mathrm{C}_{12} \mathrm{G}$ was more selective (up to $64.2 \%$ ) and molar balances nearly quantitative (97.5\%) at $160^{\circ} \mathrm{C}$, although at the expense of lower conversions and yields (see Table 1 , entry 6 ). Optimum $\mathrm{C}_{12} \mathrm{G}$ yields $(\approx 20 \%$ ) were achieved at $200{ }^{\circ} \mathrm{C}$. It should be noted that other homogeneous $\left(\mathrm{H}_{3} \mathrm{PW}_{12} \mathrm{O}_{40}\right)$ or heterogeneous (sulfonated carbon) acids are also active catalysts for the reaction (see Table S1, Supporting Information).

The results discussed above encouraged us to further optimise the reaction conditions. To face this challenge, timemonitoring experiments were undertaken for the reaction conditions leading to higher yields (Table 1 , entry $3,200^{\circ} \mathrm{C}$ ) and better selectivities (Table 1 , entry $6,160^{\circ} \mathrm{C}$ ). The conversion of cellulose is fast at $200^{\circ} \mathrm{C}$ (Figure 1 , top), although $\mathrm{C}_{12} \mathrm{G}$ yields decline at extended reaction times, with steady formation of $\mathrm{C}_{12} \mathrm{~L}$ and other by-products (see Supporting Information). By 


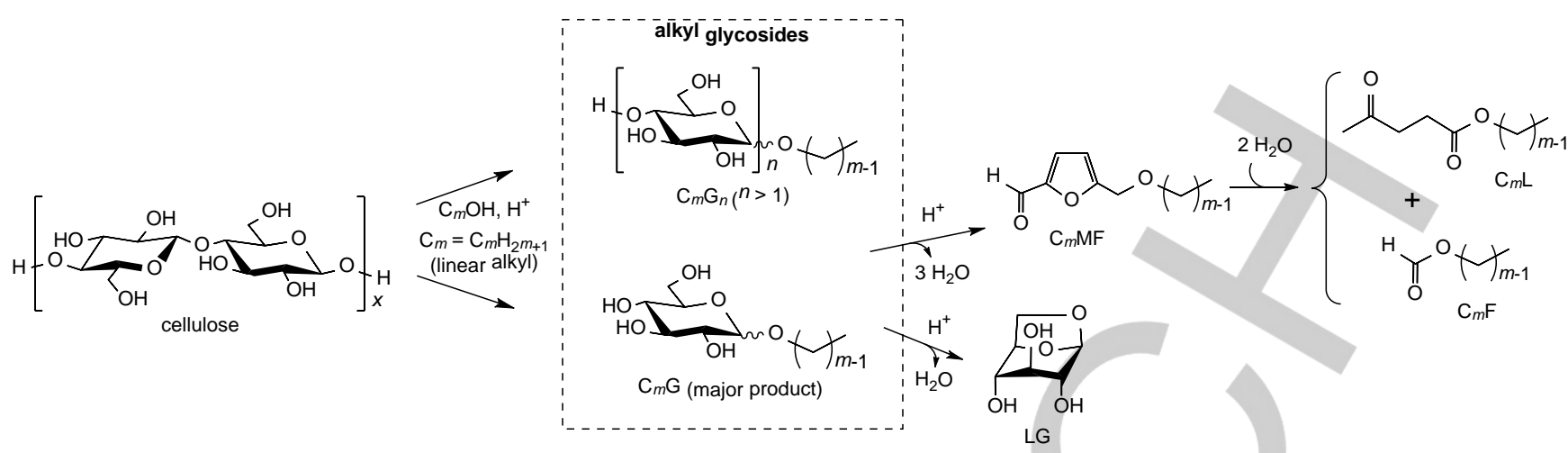

Scheme 1. Conversion of cellulose into alkyl glycosides in a direct, one-step, process in fatty alcohol $\left(\mathrm{C}_{m} \mathrm{OH}\right)$ in the presence of Brønsted acids, and main degradation reactions. Alkyl glycosides include alkyl monoglucosides $\left(\mathrm{C}_{m} \mathrm{G}\right)$ and alkyl oligoglucosides $\left(\mathrm{C}_{m} \mathrm{G}_{n}\right)$, whereas the examples of by-products shown are 5 (alkoxymethyl)furfural ( $\left.\mathrm{C}_{m} \mathrm{MF}\right)$, levoglucosan $(\mathrm{LG})$, alkyl levulinate $\left(\mathrm{C}_{m} \mathrm{~L}\right)$ and alkyl formate $\left(\mathrm{C}_{m} \mathrm{~F}\right)$

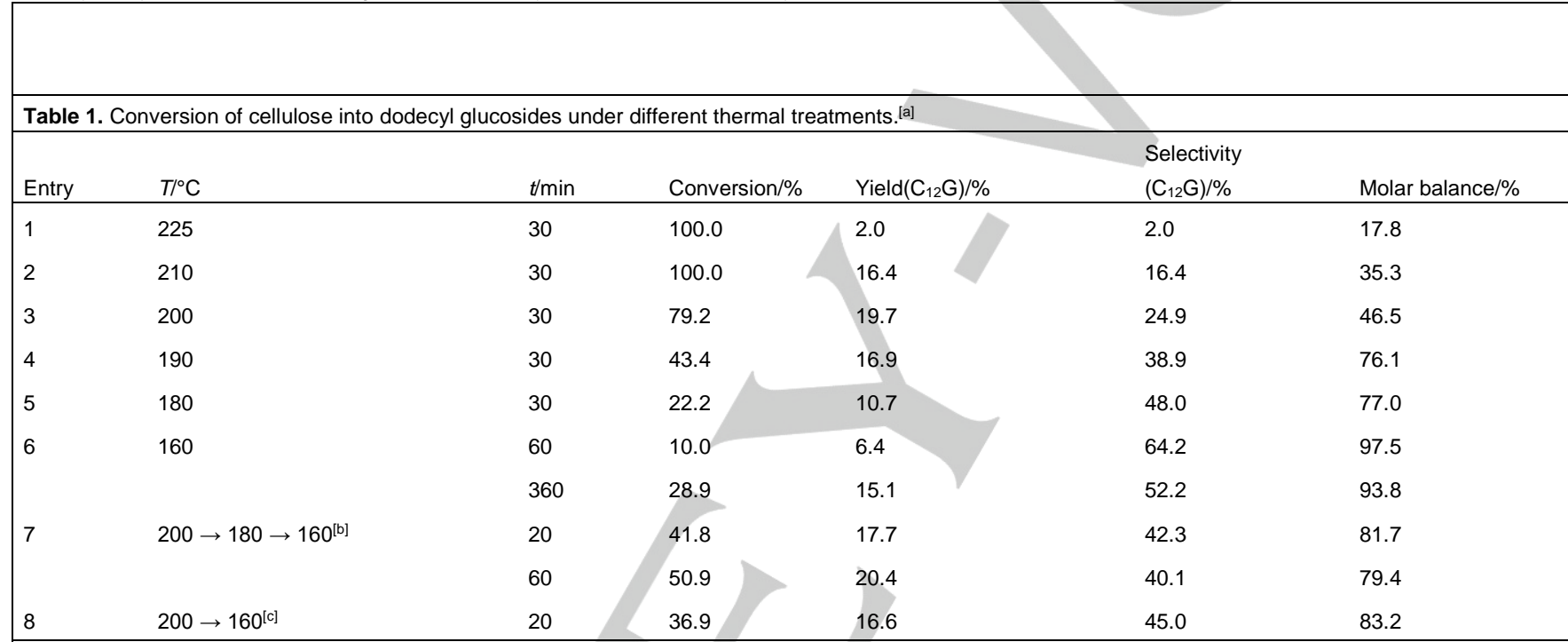

[a] Reaction conditions: cellulose $(60 \mathrm{mg})$ in 1-dodecanol $(1.0 \mathrm{~g})$ containing $\mathrm{H}_{2} \mathrm{SO}_{4}(10.8 \mathrm{mN})$, heated under the specified temperature profile, $\mathrm{N}_{2}$ atmosphere. [b] Heated at $200{ }^{\circ} \mathrm{C}$ and then, temperature decreased to $180(t=10 \mathrm{~min})$ and to $160{ }^{\circ} \mathrm{C}(t=30 \mathrm{~min})$. [c] Heated at $200{ }^{\circ} \mathrm{C}$ and then, temperature decreased to 160 $(t=0 \mathrm{~min})$.

performing the reaction at $160^{\circ} \mathrm{C}$, cellulose is slowly transformed but primarily (and preferentially) to dodecyl glycosides at short times. Longer reaction times result in steady $\mathrm{C}_{12} \mathrm{G}$ formation, although degradation becomes significant as suggested by the increasing levulinate yields (Figure 1, middle). Therefore, longer operation at lower temperatures did not provide enhancement to the efficiency of the process, and in fact, selectivity decreased after $6 \mathrm{~h}$ (Table 1, entry 6 ). Based on these facts, that is, fast conversion at $200^{\circ} \mathrm{C}$ and high selectivity at $160^{\circ} \mathrm{C}$ at short times $(<1 \mathrm{~h})$, we designed experiments whereby the reaction temperature would peak at $200^{\circ} \mathrm{C}$ at the beginning and then decrease slowly (see Table 1, entries 7 and 8, and Figure 1, bottom). This approach allowed higher $\mathrm{C}_{12} \mathrm{G}$ yields as compared to isothermal operation at $160{ }^{\circ} \mathrm{C}$, and improved selectivities (well above 40\%) as compared to the reaction performed isothermally at $200{ }^{\circ} \mathrm{C}(\approx 25 \%)$. However, increasing dodecyl levulinate yields at $>20 \mathrm{~min}$ (see Figure 1, bottom) denoted notably high rates of product decomposition, and thus impaired more effective production of surfactants. Although these results were only exploratory and more complete product analyses including higher dodecyl oligoglucosides surfactants-(see Scheme 1) would improve the results, it looked clear at this point that further optimisation required new solutions.

For this reason, two different strategies were considered: (I) addition of small amounts of water, and (ii) performance of short reaction cycles by reusing the unreacted cellulose after each cycle. The possible effect of the presence of water was taken into account in an attempt to both assist cellulose depolymerisation and minimise the dehydration reactions leading to the decomposition of surfactant products (see Scheme 1). However, an optimum concentration should be found, since too much water would have a negative effect on the formation of glycoside surfactants via hydrolysis reactions. Two experiments were performed in the presence of different amounts of water by following the best conditions based on yield and selectivity (Table 1, entry 8 ), and the results are comparatively presented in Table 2 (entries 8-10). By using a low water proportion (1:24 weight ratio relative to $\mathrm{C}_{12} \mathrm{OH}$ ), clear 

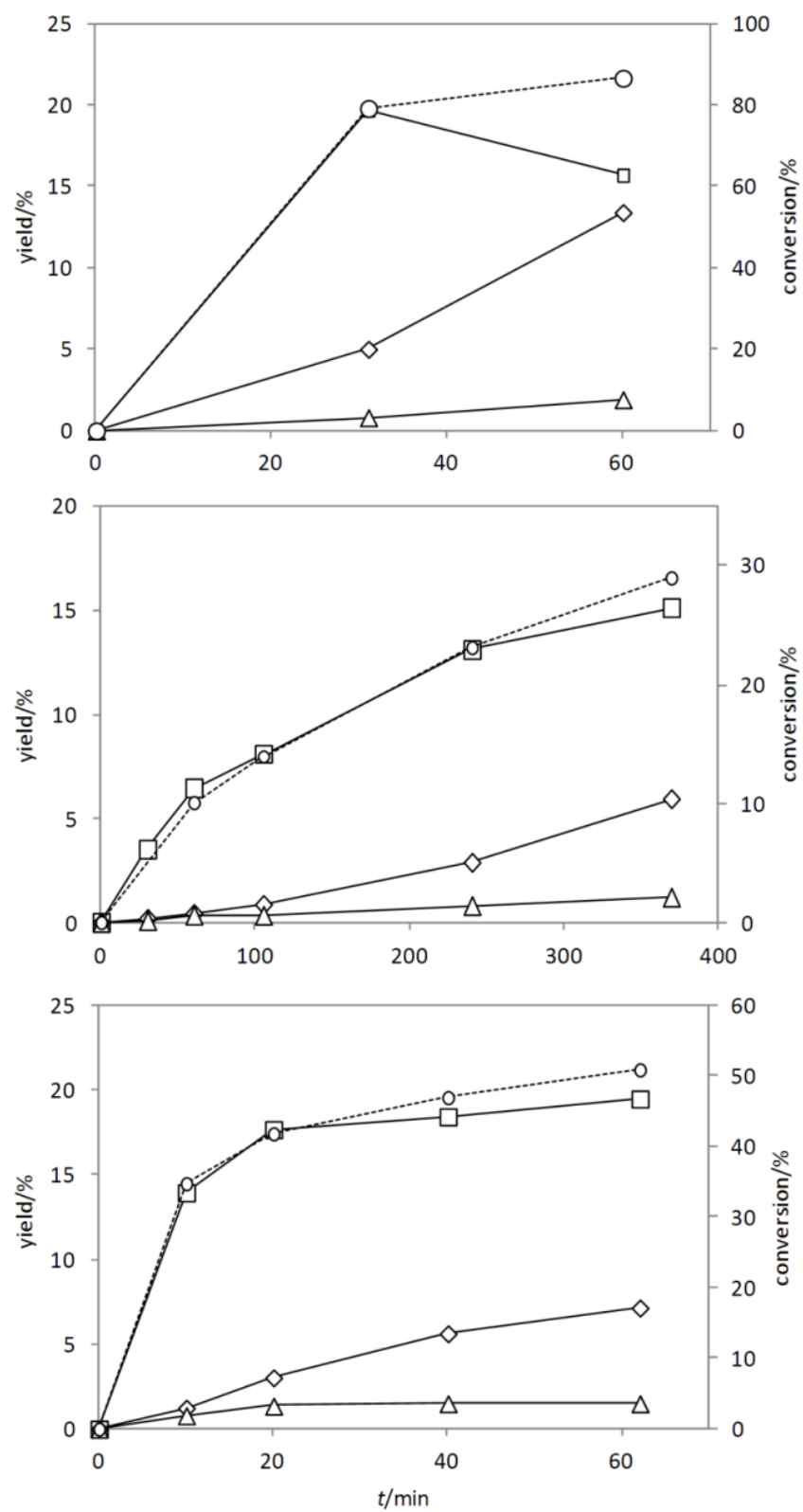

Figure 1. Time profiles for the transformation of cellulose in $\mathrm{C}_{12} \mathrm{OH} / \mathrm{H}_{2} \mathrm{SO}_{4}$ under different thermal treatments: $200{ }^{\circ} \mathrm{C}$ (top, entry 3 in Table 1 ), $160{ }^{\circ} \mathrm{C}$ (middle, entry 6 in Table 1) and at temperature decreasing from 200 to 180 (at $t=10 \mathrm{~min}$ ) and then to $160^{\circ} \mathrm{C}$ (at $t=30 \mathrm{~min}$ ), then isothermally at that temperature (bottom, entry 7 in Table 1 ). ०: conversion; $\square: C_{12} G$ yield, $\diamond: C_{12} L$ yield , $\triangle: \mathrm{C}_{12} \mathrm{MF}$ yield.

benefits were observed in terms of yield, selectivity and molar balance. A remarkable $67.7 \%$ selectivity to $\mathrm{C}_{12} \mathrm{G}$ was achieved after 20 min (see Table 2, entry 9). Longer times did not result in increased production, albeit complete analysis including dodecyl oligoglucosides $\left(\mathrm{C}_{12} \mathrm{G}_{n}, n>1\right)$ revealed that total surfactant yields in excess of $30 \%$ on a mole basis and selectivities near $70 \%$ can be attained. Working at higher water concentrations (1:9 weight ratio relative to $\mathrm{C}_{12} \mathrm{OH}$, Table 2 , entry 10 ) was detrimental for the process, since cellulose was converted to a large extent by hydrolysis to glucose and then to other degradation products (5-(hydroxymethyl)furfural, levulinic acid, etc., see Table S1), and hence, surfactant yields were low $\left(10.7 \%\right.$ for $\left.\mathrm{C}_{12} \mathrm{G}\right)$. In conclusion, though water may lead to unwanted reaction pathways, small amounts can be beneficial for surfactant production due to its role in inhibiting degradation reactions.

Another issue worth being commented here is the adventitious formation of dodecyl ether $\left(\mathrm{C}_{12} \mathrm{OC}_{12}\right)$ by selfcondensation of $\mathrm{C}_{12} \mathrm{OH}$. This was observed in all instances and thus represents a drawback for eventual process implementation (see Table S1). The ether-to-surfactant ratio $\left(\mathrm{C}_{12} \mathrm{OC}_{12} / \mathrm{C}_{12} \mathrm{G}_{n}\right)$ is taken here as a waste-to-product measure which may dictate the feasibility of this technology. As expected, $\mathrm{C}_{12} \mathrm{OC}_{12}$ formation decreased the lower the temperature, but interestingly, our strategy of adding small amounts of water also contributed to reduce it. In particular, $\mathrm{C}_{12} \mathrm{OC}_{12} / \mathrm{C}_{12} \mathrm{G}$ ratios decreased from 1.07 to 0.90 and to $0.75 \mathrm{~g} / \mathrm{g}$ for increasing water contents $\left(\mathrm{C}_{12} \mathrm{OH} / \mathrm{H}_{2} \mathrm{O}=\infty, 24: 1\right.$ and 9:1, respectively, see Table 2, entries $8-10)$. Another parameter which is here proposed to limit ether formation is the initial $\mathrm{C}_{12} \mathrm{OH} /$ cellulose ratio. In principle, employing less fatty alcohol should force it to react with cellulose more probably than with itself. In fact, this has been proven in a series of tests at increasing cellulose contents $\left(\mathrm{C}_{12} \mathrm{OH} /\right.$ cellulose $=32.4,7.3$ and $4.0 \mathrm{~g} / \mathrm{g}$ ), which resulted in decreasing final $\mathrm{C}_{12} \mathrm{OC}_{12} / \mathrm{C}_{12} \mathrm{G}$ ratios $(2.52,0.76$ and $0.24 \mathrm{~g} / \mathrm{g}$, respectively, see Table S1). It is thus clear that loading as much cellulose feedstock as possible will be beneficial to process economy, provided mass transfer (stirring efficiency) is not hindered. It should be noted that gradual addition of $\mathrm{C}_{12} \mathrm{OH}$ brought further improvements $\left(\mathrm{C}_{12} \mathrm{OC}_{12} / \mathrm{C}_{12} \mathrm{G}=0.17 \mathrm{~g} / \mathrm{g}\right.$, see Table $\left.\mathrm{S} 1\right)$.

As a final strategy aimed at increasing productivity and resource utilisation (and at the same time, minimising energy use) consists in recycling the unreacted cellulose for additional cycles with fresh fatty alcohol. On one side, it was expected that more cellulose would be converted and more surfactant would be obtained. On the other side, the focus was set on reducing the amount of $\mathrm{C}_{12} \mathrm{OH}$ used per unit mass of surfactant generated $\left(\mathrm{C}_{12} \mathrm{OH} / \mathrm{C}_{12} \mathrm{G}_{n}\right)$, which would be beneficial for process implementation as less energy would be needed for the distillation and reuse of the fatty alcohol. A first experiment analogous to entry 9 (Table 2), but done for three cycles, was performed. Conversion increased to almost quantitative levels and molar yields improved (38.7\%, entry 11 , Table 2$)$, yet $\mathrm{C}_{12} \mathrm{OH} / \mathrm{C}_{12} \mathrm{G}_{n}$ became too high. The next step consisted in starting at higher cellulose loadings (see reasoning above). Indeed, this resulted in less fatty alcohol used per surfactant product mass $\left(\mathrm{C}_{12} \mathrm{OH} / \mathrm{C}_{12} \mathrm{G}_{n}\right.$ around or below 20 , entries 12 and 13, Table 2), and in remarkably low ether by-product amounts $\left(\mathrm{C}_{12} \mathrm{OC}_{12} / \mathrm{C}_{12} \mathrm{G}_{n}=0.10 \mathrm{~g} / \mathrm{g}\right)$. Thus, it is clear that using high cellulose loading and performing short thermal cycles may be interesting approaches for process optimisation in possible biomass-to-surfactants scenarios as the ones proposed herein.

It has been proven for the first time that the conversion of cellulose into biodegradable alkyl glycoside surfactants can be carried out by direct, one-step, alcoholysis in fatty alcohol media under Brønsted acid catalysis at near-ambient pressures, thus avoiding the need to adjust conditions for multiple reactions, as for previously known two-step depolymerisation(trans)acetalysation processes. The direct one-step production 


\begin{tabular}{|c|c|c|c|c|c|c|c|c|c|c|}
\hline \multirow[b]{2}{*}{ Entry } & \multirow[b]{2}{*}{ Reaction Medium } & \multirow[b]{2}{*}{$T /{ }^{\circ} \mathrm{C}$} & \multirow[b]{2}{*}{$t / \mathrm{min}$} & \multirow[b]{2}{*}{ Conversion/\% } & \multicolumn{2}{|l|}{ Yield $/ \%$} & \multirow{2}{*}{$\begin{array}{l}\text { Selectivity } \\
\left(\mathrm{C}_{12} \mathrm{G}_{n}\right) / \%\end{array}$} & \multirow{2}{*}{$\begin{array}{r}\text { Molar } \\
\text { balancel } \\
\% \\
\end{array}$} & \multirow{2}{*}{$\begin{array}{r}\left(\mathrm{C}_{12} \mathrm{OC}_{12} /\right. \\
\left.\mathrm{C}_{12} \mathrm{G}_{n}\right) / \\
(\mathrm{g} / \mathrm{g})\end{array}$} & \multirow{2}{*}{$\begin{array}{r}\left(\mathrm{C}_{12} \mathrm{OH} /\right. \\
\left.\mathrm{C}_{12} \mathrm{G}_{n}\right) / \\
(\mathrm{g} / \mathrm{g}) \\
\end{array}$} \\
\hline & & & & & $\mathrm{C}_{12} \mathrm{G}$ & $\mathrm{C}_{12} \mathrm{G}_{n}$ & & & & \\
\hline 8 & $\mathrm{C}_{12} \mathrm{OH}$ & $200 \rightarrow 160$ & 20 & 36.9 & 16.6 & & 45.0 & 83.2 & 1.07 & \\
\hline \multirow[t]{2}{*}{9} & $\mathrm{C}_{12} \mathrm{OH} / \mathrm{H}_{2} \mathrm{O}(24: 1)$ & $200 \rightarrow 160$ & 20 & 35.8 & 24.3 & & 67.7 & 95.8 & 0.90 & \\
\hline & & & 40 & 45.9 & 24.1 & 31.4 & 68.5 & 94.8 & 0.40 & 25.0 \\
\hline 10 & $\mathrm{C}_{12} \mathrm{OH} / \mathrm{H}_{2} \mathrm{O}(9: 1)$ & $200 \rightarrow 160$ & 20 & 79.4 & 10.7 & & 13.5 & 59.9 & 0.75 & \\
\hline 11 & $\mathrm{C}_{12} \mathrm{OH} / \mathrm{H}_{2} \mathrm{O}(24: 1) \times 3^{[\mathrm{b}]}$ & $200 \rightarrow 160$ & $20 \times 3$ & 92.8 & 36.7 & 38.7 & 41.8 & 54.7 & 0.61 & 57.6 \\
\hline 12 & $\mathrm{C}_{12} \mathrm{OH} / \mathrm{H}_{2} \mathrm{O}(24: 1) \times 3^{[b, c]}$ & $200 \rightarrow 160$ & $20 \times 3$ & 55.1 & 21.3 & 24.2 & 43.9 & 81.3 & 0.10 & 22.8 \\
\hline 13 & $\mathrm{C}_{12} \mathrm{OH} / \mathrm{H}_{2} \mathrm{O}(24: 1) \times 3^{[\mathrm{b}, \mathrm{d}]}$ & $200 \rightarrow 160$ & $20 \times 3$ & 43.5 & 17.7 & 21.2 & 48.8 & 91.4 & 0.13 & 19.8 \\
\hline
\end{tabular}

[a] Reaction conditions: cellulose (60 mg, unless otherwise stated) in $\mathrm{C}_{12} \mathrm{OH}$ or $\mathrm{C}_{12} \mathrm{OH} / \mathrm{H}_{2} \mathrm{O}$ mixtures (1.0 g, weight ratio as specified) containing $\mathrm{H}_{2} \mathrm{SO}$ $(10.8 \mathrm{mN})$, heated to $200^{\circ} \mathrm{C}$ and then temperature decreased to $160^{\circ} \mathrm{C}, \mathrm{N}_{2}$ atmosphere. [b] The reaction was performed for three cycles by centrifugingdecanting the unreacted cellulose after each cycle. [c] $w t$ (cellulose) $=250 \mathrm{mg}$. [d] $w t$ (cellulose) $=250 \mathrm{mg} . w t\left(\mathrm{C}_{12} \mathrm{OH} / \mathrm{H}_{2} \mathrm{O}\right)=0.75 \mathrm{~g}$.

reported herein is fast and effective via short thermal procedures whereby temperatures first reach a peak and then are allowed to slowly decrease. Selectivities were enhanced $(\approx 70 \%)$ by addition of small amounts of water ( $<5 \%$ by weight), due to inhibition of glucoside degradation (dehydration). Further improvements of process outcome parameters-higher yields, reduced use of fatty alcohol per surfactant mass, and limited self-condensation of the alcohol into fatty ether-were achieved by maximising substrate loading and submitting the unreacted cellulose to successive reaction cycles. The observed results and trends are encouraging for the plausible implementation of this direct biomass-to-surfactants methodology.

\section{Supporting Information Summary}

Materials description, alcoholysis procedures, description of analytical methods, synthetic procedures for standard compounds (1-dodecyl ether and 1-dodecyl levulinate) and complete reaction data are given in the Supporting Information file.

\section{Acknowledgements}

Financial support from the Spanish Government-MINECO through "Severo Ochoa" (SEV 2012-0267) is acknowledged. AVP also thanks the Spanish Government (Agencia Estatal de Investigación) and the European Union (European Regional Development Fund) for a grant for young researchers (CTQ2015-74138-JIN, AEI/FEDER/UE).

Keywords: Acid catalysis, Biomass, Cellulose, Process intensification, Surfactant.

[1] a) A. Corma, S. Iborra, A. Velty, Chem. Rev. 2007, 107, 24112502; b) M. J. Climent, A. Corma, S. Iborra, Green Chem. 2011 13, 520-540; c) R. A. Sheldon, Green Chem. 2014, 16, 950-963; d) M. J. Climent, A. Corma, S. Iborra, Green Chem. 2014, 16, 516547. A. Dumesic, Chem. Soc. Rev. 2012, 41, 8075-8098. a) J. A. Geboers, d. V. S. Van, R. Ooms, d. B. B. Op, P. A. Jacobs B. F. Sels, Catal. Sci. Technol. 2011, 1, 38-50; b) S. Van De Vyver, J. Geboers, P. A. Jacobs, B. F. Sels, ChemCatChem 2011, 3, 8294; c) H. Kobayashi, H. Ohta, A. Fukuoka, Catal. Sci. Technol. 2012, 2, 869-883; d) H. Kobayashi, T. Komanoya, S. K. Guha, K. Hara, A. Fukuoka, Appl. Catal., A 2011, 409, 13-20.

[4] R. Palkovits, K. Tajvidi, J. Procelewska, R. Rinaldi, A. Ruppert Green Chem. 2010, 12, 972-978.

[5] a) Y. Wang, W. Deng, B. Wang, Q. Zhang, X. Wan, Z. Tang, Y. Wang, C. Zhu, Z. Cao, G. Wang, H. Wan, Nat. Commun. 2013, 4 3141/3141-3141/3147; b) F. Chambon, F. Rataboul, C. Pinel, A. Cabiac, E. Guillon, N. Essayem, Appl. Catal., B 2011, 105, 171181.

[6] a) S. Yu, H. M. Brown, X. W. Huang, X. D. Zhou, J. E. Amonette, Z C. Zhang, Appl. Catal., A 2009, 361, 117-122; b) J. N. Chheda, Y. Roman-Leshkov, J. A. Dumesic, Green Chem. 2007, 9, 342-350. a) W. von Rybinski, K. Hill, Angew. Chem.-Int. Edit. 1998, 37 1328-1345; b) P. Foley, P. A. Kermanshahi, E. S. Beach, J. B. Zimmerman, Chem. Soc. Rev. 2012, 41, 1499-1518.

[8] a) N. Villandier, A. Corma, ChemSusChem 2011, 4, 508-513; b) N Villandier, A. Corma, Chem. Commun. 2010, 46, 4408-4410; c) A V. Puga, A. Corma, ChemSusChem 2014, 7, 3362-3373.

[9] I. A. Ignatyev, P. G. N. Mertens, C. Van Doorslaer, K. Binnemans, D. E. de Vos, Green Chem. 2010, 12, 1790-1795. a) W. Deng, M. Liu, Q. Zhang, X. Tan, Y. Wang, Chem. Commun. 2010, 46, 2668-2670; b) W. Deng, M. Liu, Q. Zhang, Y. Wang, Catal. Today 2011, 164, 461-466; c) J. Feng, J. Jiang, J. Xu, Z. Yang, RSC Adv. 2015, 5, 38783-38791; d) D. Ding, J. Xi, J. Wang, X. Liu, G. Lu, Y. Wang, Green Chem. 2015, 17, 4037-4044; e) L. Xue, K. Cheng, H. Zhang, W. Deng, Q. Zhang, Y. Wang, Catal. Today 2016, 274, 60-66. 
Entry for the Table of Contents (Please choose one layout)

Layout 1:

\section{COMMUNICATION}

The direct production of biodegradable alkyl glycoside surfactants from cellulose in a single step has been achieved in fatty alcohol media under Brønsted acid catalysis at near-ambient pressure; addition of small amounts of water and short thermal cycles enable moderate-to-high conversions and selectivities (up to $\approx 70 \%$ ), and low solvent-to-product ratios.
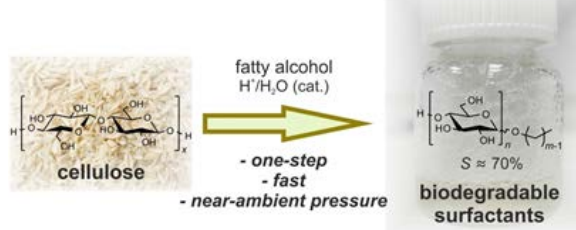

A. V. Puga, A. Corma*

Page No. - Page No.

Direct Conversion of Cellulose into Alkyl Glycoside Surfactants

Layout 2:

COMMUNICATION

A. V. Puga, A. Corma*

Page No. - Page No.

Direct conversion of cellulose into alkyl glycoside surfactants

Text for Table of Contents 